\title{
Recovery of Vision following Enzyme Replacement Therapy in a Patient with Mucopolysaccharidosis Type II, Hunter Syndrome
}

\author{
Ryutaro Yamanishi, ${ }^{a, c} \quad$ Natsuko Nakamura ${ }^{b, d} \quad K^{2}$ azushige Tsunoda ${ }^{a, b}$ \\ aDepartment of Ophthalmology, National Hospital Organization Tokyo Medical Center, \\ Tokyo, Japan; bivision of Vision Research, National Institute of Sensory Organs, \\ National Hospital Organization Tokyo Medical Center, Tokyo, Japan; 'Department of \\ Ophthalmology, Keio University, Tokyo, Japan; dDepartment of Ophthalmology, \\ The University of Tokyo, Tokyo, Japan
}

\section{Keywords}

Hunter syndrome · Mucopolysaccharidosis type II - Enzyme replacement therapy · Idursulfase · Vision · Recovery

\begin{abstract}
We analyzed the effects of enzyme replacement therapy (ERT) on the visual acuity and visual fields of a patient with mucopolysaccharidosis type II, Hunter syndrome, with degeneration of the retina and abnormalities of the optic nerve. After the ERT, there was an improvement of the visual acuity and visual fields and an improvement of the activities of daily living. Despite the late onset of Hunter syndrome in this patient, ERT was still able to improve the visual function. We conclude that ERT should be considered regardless of the age of the manifestations of the signs and symptoms of Hunter syndrome.




\section{Case Reports in Ophthalmology}

Case Rep Ophthalmol 2019;10:186-194

(C) 2019 The Author(s). Published by S. Karger AG, Base www.karger.com/cop

Yamanishi et al.: Recovery of Vision following Enzyme Replacement Therapy in a Patient with Mucopolysaccharidosis Type II, Hunter Syndrome

\section{Introduction}

Mucopolysaccharidosis (MPS) type II or Hunter syndrome is a disorder caused by inherited defects in the lysosomal enzyme, iduronate-2-sulfatase, that results in the deposition of the glycosaminoglycan, dermatan sulfate, and heparan sulfate in the lysosomes. The ocular abnormalities in Hunter syndrome include exophthalmos, hypertelorism, corneal opacification, pigmentary retinopathy, and optic nerve atrophy [1]. We present a case of Hunter syndrome with poor vision due to retinal degeneration and optic nerve abnormalities whose vision recovered following enzyme replacement therapy (ERT) [2, 3]. To the best of our knowledge, this is the first case study that documents the course of visual improvement following ERT in a patient with Hunter syndrome.

\section{Case Report/Case Presentation}

A 38-year-old Japanese man was referred to our hospital because of a progressive decrease in his visual acuity in both eyes. At the initial visit, the patient's facial features were gargoyle-like. His decimal best-corrected visual acuity (BCVA) was 0.2 in his right eye and no light perception in his left eye. Goldmann perimetry showed an afferent constriction of 5 degrees in the visual field of the right eye. His corneas were clear bilaterally. Ophthalmoscopic examinations showed a salt-and-pepper appearance of the retinal pigment epithelium (RPE) over the entire retina. The optic discs appeared slightly pale and mildly elevated from the retina (Fig. 1a). Fundus autofluorescence (FAF) imaging demonstrated hypo-FAF in the entire posterior pole with patchy absence of FAF around the macula (Fig. 1b). Optical coherence tomography (OCT) demonstrated diffuse atrophy of the photoreceptors and RPE layers, relatively well-preserved fovea with thickened external limiting membrane, multiple cysts in the inner plexiform layer, thinning of the ganglion cell and nerve fiver layers, and sawtooth appearance of the inner limiting membrane (Fig. 2).

He was referred to a lysosome disease center. Enzyme assays found that the urinate glycosaminoglycan was elevated to $98.9 \mathrm{mg} / \mathrm{g}$ creatinine (normal level $29.3 \pm 13.3 \mathrm{mg} / \mathrm{g}$ creatinine), and iduronate-2-sulfatase level was reduced to less than $1.2 \mathrm{nmol} / \mathrm{mg}$ protein $/ 4 \mathrm{~h}$ (normal level 58.4-114 nmol/mg protein/4 h). A diagnosis of a mild form of Hunter syndrome was confirmed at the lysosome disease center. Magnetic resonance imaging (MRI) of the brain showed hydrocephalus and enlargement of the lateral ventricles, which are typical findings of Hunter syndrome.

Because the BCVA of his right eye was decreased to hand motion at the age of 39 years, he agreed to begin ERT, and $0.5 \mathrm{mg} / \mathrm{kg}(30.0 \mathrm{mg})$ of idursulfase (Elaprase $\left.{ }^{\mathrm{TM}}\right)$ was given intravenously weekly. After beginning the ERT, his vision gradually improved, and within 1 week, he noticed a reduction of the degree of blurred vision in both eyes. He reported that he could perceive light in his left eye. Six months after beginning the ERT, he noticed an expansion of his peripheral visual field in his right eye, and at 9 months, he could recognize captions on the TV and location of clock hands, although the BCVA in his right eye was still hand motion. Twelve months after the ERT, he could recognize patterns of the newscaster's necktie on TV, and at 15 months, he could recognize the numbers on an LCD monitor in our outpatient clinic. 
At 18 months after the ERT, the decimal BCVA had improved to 0.05 in the right eye, and the peripheral visual field had expanded. The improvement in the BCVA and visual field in the right eye are shown in Fig. 3. Together with the improvement of vision, the patient reported significant recoveries of the activities of daily living (Table 1).

The appearance of the fundus, OCT image, and FAF image did not show any significant changes during the course. We had planned to follow his visual function, but he died due to cardiovascular disease at the age of 41 years.

\section{Discussion/Conclusion}

To the best of our knowledge, this is the first case report of a patient with Hunter syndrome that documented the course of the visual improvements following ERT. A PubMed search in March 2019 using the keywords "Hunter syndrome," "MPS type II," "enzyme treatment therapy," and "visual function" did not extract any publications describing the recovery of visual function after ERT in a Hunter syndrome patient.

The pre-ERT ophthalmoscopic findings of our patient resembled those reported $[4,5]$, viz., salt-and-pepper appearance of the RPE with macular sparing and mild pallor and elevated optic disc. A previous report indicated that corneal opacity usually occurs in Hunter syndrome, but does not impair vision in contrast to MPS type I (Hurler-Scheie syndrome) [1]. In addition, OCT showed diffuse atrophy of the photoreceptors and RPE, relatively well-preserved fovea with thickened external limiting membrane, multiple cysts in the inner plexiform layer, thinning of the ganglion cell and nerve fiver layers, and sawtooth appearance of the inner limiting membrane. These are the typical findings reported for patients with Hunter syndrome $[4,5]$. Our patient presented with the typical ocular manifestations of the mild form of Hunter syndrome.

During the ERT, objective examinations of this patient by ophthalmoscopy, OCT, FAF, and ERG did not demonstrate either a recovery or progression. The improvement of visual function could thus be estimated by the BCVA and visual field tests. Because the BCVA was in the low vision range and central fixation was lost at the beginning of ERT, it might seem difficult to accurately evaluate the course of visual improvement. However, detailed reports of vision in the patient's daily living strongly supported the improvement of visual function after the ERT (Table 1).

There are several reports on patients with MPS type I, also known as Hurler, HurlerScheie, and Scheie syndrome, in whom the visual course after ERT has been documented [6, 7]. Pitz et al. [6] presented eight cases with MPS type I who were treated with ERT. The ocular findings remained stable in most patients, and the ERT did not seem to prevent the progression of the corneal or optic disc changes. They reported a worsening of the visual function. Our case of Hunter syndrome did not have corneal clouding and the recovery of vision was most likely an improvement of the more central visual system following ERT. The exact mechanism for the recovery of vision in this case was not definitively determined. In this case, the central visual field had been lost although the photoreceptor structures at the fovea in the OCT images and light-adapted ERGs were relatively well preserved. Thus, the visual impairments were attributed not only to retinal degeneration but also to optic nerve atrophy. 


\section{Case Reports in Ophthalmology}

Idursulfase does not cross the blood-brain barrier and may also not cross the blood-retinal barrier. Thus, it is likely that ERT did not contribute to the recovery of retinal functions, but the recovery of vision was due to recovery of optic nerve function. Previous reports suggested that a blood-brain barrier was not present in the optic nerve head [8]. Thus, the effectiveness of the ERT through the optic nerve head may also be considered. There are histopathological studies of Hunter syndrome, and the findings indicate a possible contribution of the optic nerve to the visual impairment. There were multiple membranous lamellar vacuoles in the cytoplasm of retinal ganglion cells and the number of cells was reduced [9-11]. The accumulation of glycosaminoglycan within the ganglion cells can lead to their degeneration and optic atrophy. Moreover, the deposition of abnormal mucopolysaccharides within the dura and sclera can cause a gross thickening of the sclera, and this can lead to a compression of the optic nerve at the level of the lamina cribrosa [12]. In addition, there is another possibility that both decrease and recovery of visual function were associated with intracranial changes such as hydrocephalus. However, the MRI was examined only once during the followup period and the association between visual symptoms and intracranial changes could not be determined.

In conclusion, ERT can lead to a recovery of the visual acuity and visual fields in a patient with Hunter syndrome, although the long course of the disease process led to severe damage to the retina and optic nerve. We recommend ERT for patients with Hunter syndrome even after the vision has been reduced to hand motion.

\section{Statement of Ethics}

The procedures used adhered to the tenets of the Declaration of Helsinki, and approval to perform this study was obtained from the Review Board/Ethics Committee of the National Institute of Sensory Organs, National Hospital Organization Tokyo Medical Center (Reference: R18-029). In addition, written informed consent was obtained from the patient.

\section{Disclosure Statement}

The authors have no conflicts of interest to declare.

\section{Funding Sources}

This study is supported by research grants from National Hospital Organization Network Research Fund (H30-NHO-Sensory Organs-03 to K.T.). The authors have no proprietary or commercial interest in any materials discussed in this article. 


\section{Case Reports in Ophthalmology}

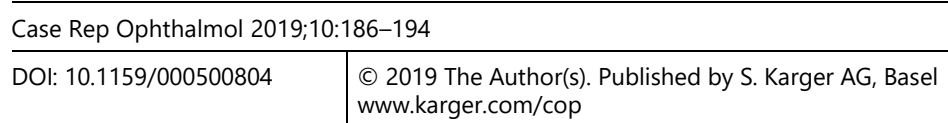

Yamanishi et al.: Recovery of Vision following Enzyme Replacement Therapy in a Patient with Mucopolysaccharidosis Type II, Hunter Syndrome

\section{References}

1 Ashworth JL, Biswas S, Wraith E, Lloyd IC. Mucopolysaccharidoses and the eye. Surv Ophthalmol. 2006 JanFeb;51(1):1-17.

2 Burrow TA, Leslie ND. Review of the use of idursulfase in the treatment of mucopolysaccharidosis II. Biologics. 2008 Jun;2(2):311-20.

3 Parini R, Rigoldi M, Tedesco L, Boffi L, Brambilla A, Bertoletti S, et al. Enzymatic replacement therapy for Hunter disease: up to 9 years experience with 17 patients. Mol Genet Metab Rep. 2015 Apr;3:65-74.

4 Yoon MK, Chen RW, Hedges TR 3rd, Srinivasan VJ, Gorczynska I, Fujimoto JG, et al. High-speed, ultrahigh resolution optical coherence tomography of the retina in Hunter syndrome. Ophthalmic Surg Lasers Imaging. 2007 Sep-Oct;38(5):423-8.

5 Seok S, Lyu IJ, Park KA, Oh SY. Spectral domain optical coherence tomography imaging of mucopolysaccharidoses I, II, and VI A. Graefes Arch Klin Exp Ophthalmol. 2015 Dec;253(12):2111-9.

6 Pitz S, Ogun O, Bajbouj M, Arash L, Schulze-Frenking G, Beck M. Ocular changes in patients with mucopolysaccharidosis I receiving enzyme replacement therapy: a 4-year experience. Arch Ophthalmol. 2007 Oct;125(10):1353-6.

7 Mack HG, Symons RC, de Jong G. Bull's eye maculopathy and subfoveal deposition in two mucopolysaccharidosis type I patients on long-term enzyme replacement therapy. Am J Ophthalmol Case Rep. 2017 Oct; 9:1-6.

8 Tso MO, Shih CY, McLean IW. Is there a blood-brain barrier at the optic nerve head? Arch Ophthalmol. 1975 Sep;93(9):815-25.

9 Goldberg MF, Duke JR. Ocular histopathology in Hunter's syndrome. Systemic mucopolysaccharidosis type II. Arch Ophthalmol. 1967 Apr;77(4):503-12.

10 Topping TM, Kenyon KR, Goldberg MF, Maumenee AE. Ultrastructural ocular pathology of Hunter's syndrome. Systemic mucopolysaccharidosis type II. Arch Ophthalmol. 1971 Aug;86(2):164-77.

11 McDonnell JM, Green WR, Maumenee IH. Ocular histopathology of systemic mucopolysaccharidosis, type II-A (Hunter syndrome, severe). Ophthalmology. 1985 Dec;92(12):1772-9.

12 Beck M, Cole G. Disc oedema in association with Hunter's syndrome: ocular histopathological findings. Br J Ophthalmol. 1984 Aug;68(8):590-4. 


\section{Case Reports in Ophthalmology}

Case Rep Ophthalmol 2019;10:186-194

(C) 2019 The Author(s). Published by S. Karger AG, Basel DOI: $10.1159 / 000500804$ www.karger.com/cop

Yamanishi et al.: Recovery of Vision following Enzyme Replacement Therapy in a Patient with Mucopolysaccharidosis Type II, Hunter Syndrome
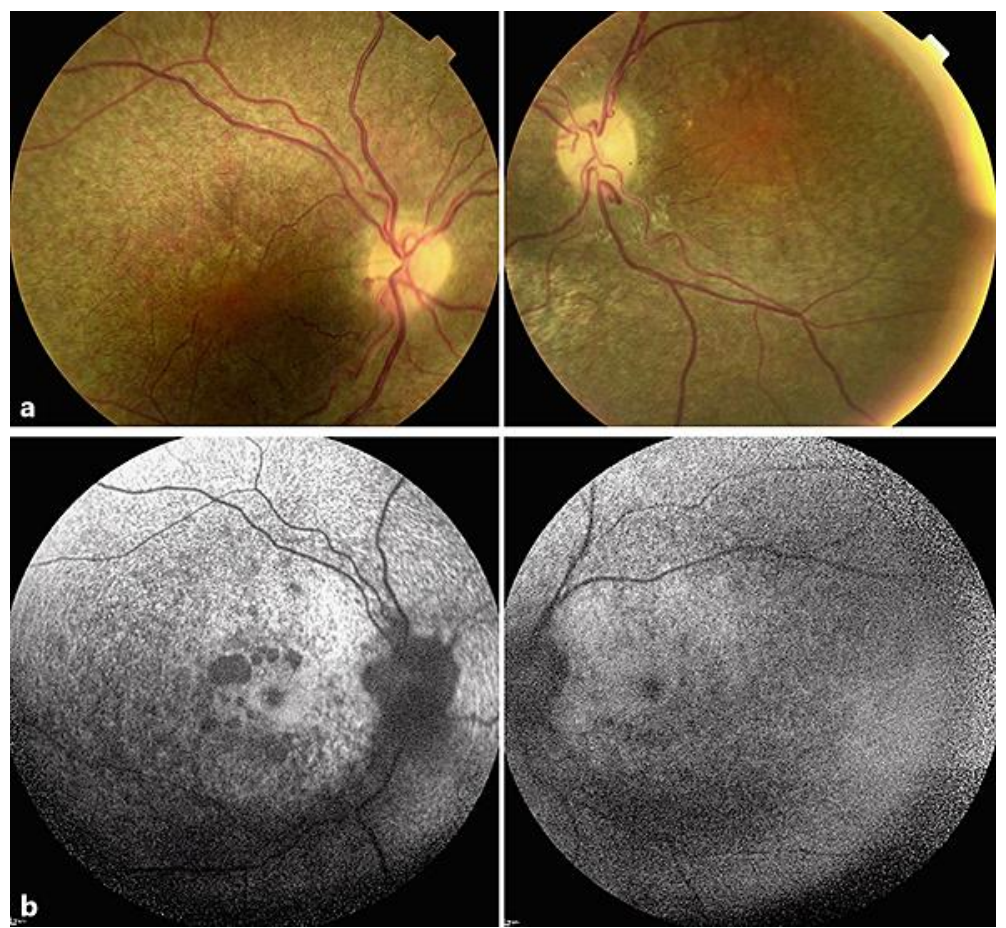

Fig. 1. Fundus photographs and fundus autofluorescence (FAF) images of a case with mucopolysaccharidosis type II, Hunter syndrome. a Fundus photographs show salt-and-pepper appearance of the retinal pigment epithelium over the entire retina. The optic discs appear mildly pale and slightly elevated from the retina. b FAF image shows hypo-FAF over the entire posterior pole with patchy absence of FAF around the macula. 


\section{Case Reports in Ophthalmology}

Case Rep Ophthalmol 2019;10:186-194

(C) 2019 The Author(s). Published by S. Karger AG, Basel DOI: $10.1159 / 000500804$ www.karger.com/cop

Yamanishi et al.: Recovery of Vision following Enzyme Replacement Therapy in a Patient with Mucopolysaccharidosis Type II, Hunter Syndrome
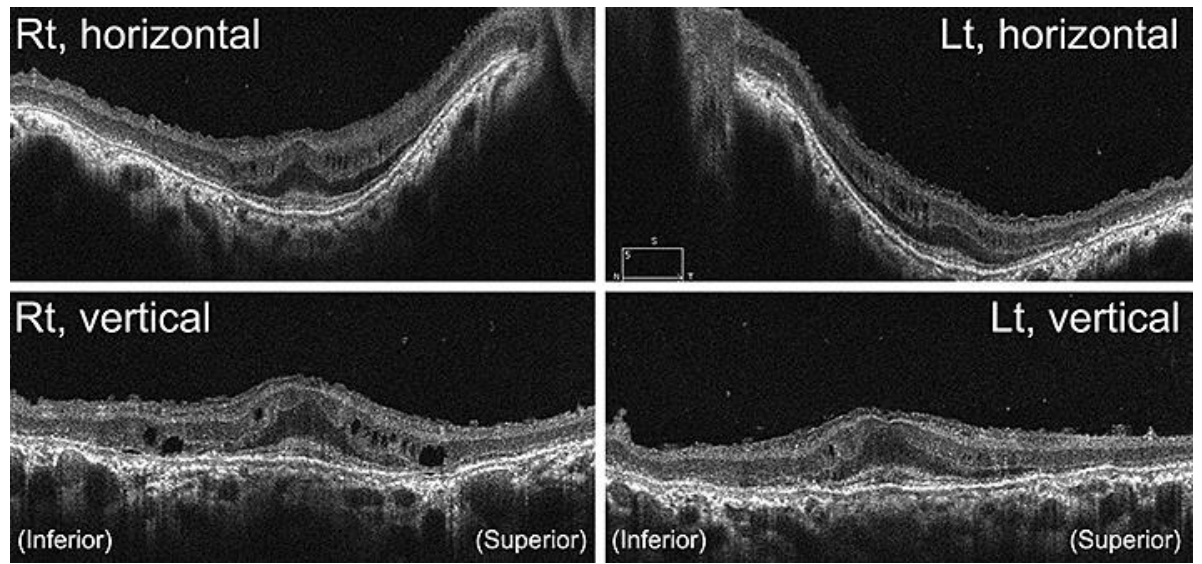

Fig. 2. Optical coherence tomographic (OCT) image of the retina of a case with mucopolysaccharidosis type II, Hunter syndrome. The OCT image demonstrates diffuse atrophy of the photoreceptor and RPE layers, relatively well-preserved fovea with thickened external limiting membrane, multiple cysts in the inner plexiform layer, thinning of the ganglion cell and nerve fiver layers, and sawtooth appearance of the inner limiting membrane. 


\section{Case Reports in Ophthalmology}

Case Rep Ophthalmol 2019;10:186-194

(c) 2019 The Author(s). Published by S. Karger AG, Base www.karger.com/cop

Yamanishi et al.: Recovery of Vision following Enzyme Replacement Therapy in a Patient with Mucopolysaccharidosis Type II, Hunter Syndrome
(Before ERT)

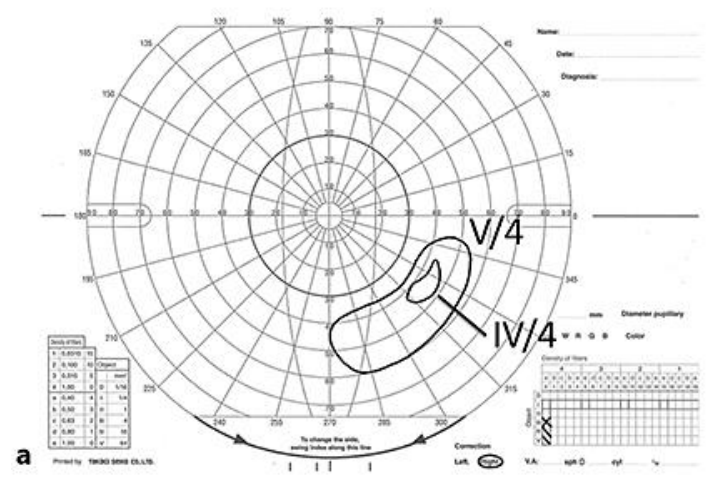

(18M after ERT)

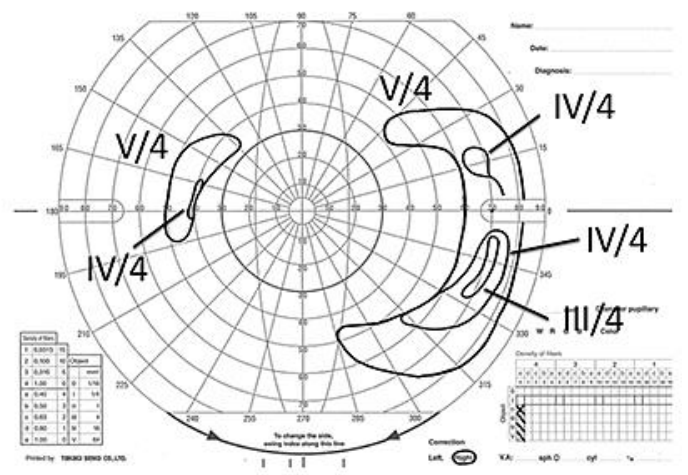

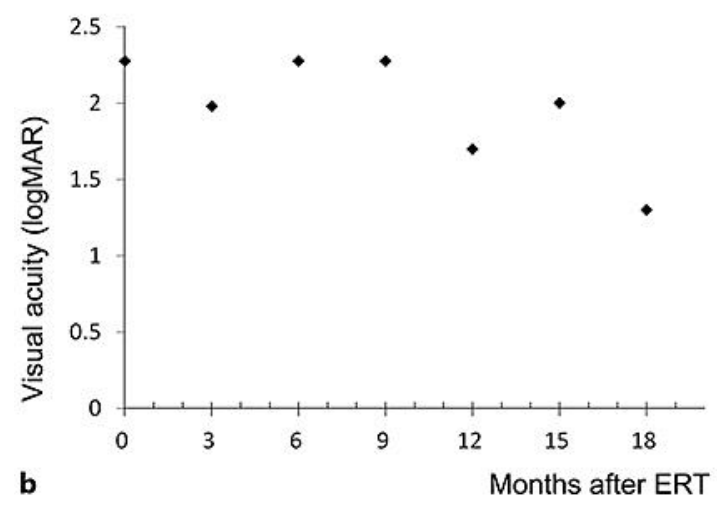

Fig. 3. Time course of the best-corrected visual acuity (logMAR units) and visual fields determined by Goldmann perimetry of a case with mucopolysaccharidosis type II, Hunter syndrome following enzyme replacement therapy (ERT). a Goldmann perimetry of the right eye, before (left) and 18 months after (right) the ERT. $\mathbf{b}$ Course of best-corrected visual acuity of the right eye in logMAR units. Eighteen months after the ERT (December 2016), the best-corrected visual acuity has improved, and peripheral visual field has expanded. The visual acuity of counting fingers and hand motion was improved to 1.98 and $2.28 \operatorname{logMAR}$ units according to the Lange et al. [12] conversion table. 
Table 1. Course of visual function and activities of daily living after receiving enzyme replacement therapy

\begin{tabular}{|c|c|c|c|c|}
\hline \multirow{2}{*}{$\begin{array}{l}\text { Months after } \\
\text { initiation of } \\
\text { ERT }\end{array}$} & \multicolumn{2}{|c|}{ Decimal visual acuity } & \multirow{2}{*}{$\begin{array}{l}\text { Patient's report on vision in daily } \\
\text { living }\end{array}$} & \multirow{2}{*}{$\begin{array}{l}\text { Systemic changes and activities of } \\
\text { daily living }\end{array}$} \\
\hline & OD & OS & & \\
\hline 0 & $\mathrm{HM}$ & $\mathrm{LP}(-)$ & & \\
\hline 3 & $\begin{array}{l}\text { counting } \\
\text { fingers }\end{array}$ & $\mathrm{LP}(+)$ & Decrease in blurred vision OU & $\begin{array}{l}\text { Improved mobility of ankle joints; } \\
\text { reduction of hepatomegaly and } \\
\text { splenomegaly }\end{array}$ \\
\hline 6 & $\mathrm{HM}$ & LP (+) & $\begin{array}{l}\text { Recovery of peripheral visual field } \\
\text { OD }\end{array}$ & $\begin{array}{l}\text { Decrease in swelling and } \\
\text { improvement of mobility of } \\
\text { fingers and elbows }\end{array}$ \\
\hline 9 & $\mathrm{HM}$ & $\mathrm{LP}( \pm)$ & $\begin{array}{l}\text { Able to recognize captions on } \mathrm{TV} \\
\text { and location of clock hands }\end{array}$ & $\begin{array}{l}\text { Able to walk in house with } \\
\text { assistance }\end{array}$ \\
\hline 12 & 0.02 & $\mathrm{LP}( \pm)$ & $\begin{array}{l}\text { Able to recognize patterns of } \\
\text { newscaster's necktie on TV }\end{array}$ & \\
\hline 15 & 0.01 & $\mathrm{LP}( \pm)$ & $\begin{array}{l}\text { Able to read numbers on an LCD } \\
\text { monitor in outpatient clinic }\end{array}$ & \\
\hline 18 & 0.05 & $\mathrm{LP}( \pm)$ & & Able to walk without assistance \\
\hline
\end{tabular}

HM, hand motion; LP, light perception. 